\title{
The influence of computer generated animations on juror decision making
}

\author{
By Gareth Norris
}

The modern court is changing and part of this development is a result of the increased use of technology. In particular, the use of multimedia applications have enabled legal teams to present evidence in new and novel ways; however, animations and computer generated exhibits (CGE) have recently been the subject of debate over their potential to unduly influence court decisions. A growing body of empirical studies in this area suggests that major differences in trial outcome could result from the inclusion of animation evidence. Subtle changes to the style and format of CGEs can be problematic and produce disparate outcomes in experimental studies. This paper reviews some of the leading research and commentary in the field of electronic court evidence, with an emphasis on juror decision making. Specifically, it outlines the way in which decision making errors (for example, the hindsight bias) are unduly influenced by animation evidence and the way in which CGEs can initiate features of jury decision models (e.g. the 'critical event' in Stochastic Processing). The use of CGE in recent cases will be discussed along with suggestions for potential policy implications and avenues of future research.

\section{Introduction}

The increased use of multi-media, animations and computer generated exhibits (CGE) in the court has raised a number of concerns from legal professionals and academics alike. ${ }^{1}$ In particular, their potential to unduly influence or even mislead jurors and other legal decision makers (e.g. coroners), extends beyond issues surrounding the style and quality of these

\footnotetext{
${ }^{1}$ Megan A. Dunn, Peter Salovey, and Neal Feigenson, 'The Jury Persuaded (and Not): Computer Animation in the Courtroom', Law \& Policy, Volume 28, Issue 2, 2006, 228-248; Damian Schofield and Stephen Mason, Using Graphical Technology to Present Evidence. In Stephen Mason, general editor, Electronic Evidence (3rd Edition, London: LexisNexis, 2012), Chapter 6; Gareth Norris, ' The shortcomings of computer-generated exhibits', Criminal Law and Justice Weekly, Volume 177, Issue 40, 2013, 808-809.
}

presentations. ${ }^{2}$ Previously, the conventional wisdom held that the use of multi-media in court was essentially no different to more established methods - the 'chalkboard and easel' - and that good preparation and inventive delivery was not fundamentally different in the age of multi-media technology than in previous decades. ${ }^{3}$ However, more recently, and as the capabilities of the 'tools' have pushed the boundaries of what is possible (for example, immersive Virtual Reality), commentators are suggesting a more systematic approach to reviewing these practices. ${ }^{4}$ To date, there are only a limited number of relatively separate empirical studies and more general legal opinions that serve to curtail an otherwise expanding industry in trial support software and litigation consultancy.

Many of these empirical examinations of CGE have demonstrated that different outcomes (e.g. guilty/not guilty) are possible when animations are introduced into experimental scenarios with samples of mock jurors serving as participants. ${ }^{5}$ One of the earliest and most cited empirical examples was by Saul Kassin and Megan Dunn, where they demonstrated the influence the introduction of an animation had on an equivocal suicide case. ${ }^{6}$ Theoretically, the different positions in which the body was discovered illustrated the poor understanding that the subjects (mock jurors) had for the physical behaviour of falling objects. It was demonstrated that it was experimentally feasible to

\footnotetext{
${ }^{2}$ Neal Feigenson, 'Visual evidence', Psychonomic Bulletin \& Review, Volume 17, Issue 2, 2010, 149-154.

${ }^{3}$ Fred Galves, 'Where the not-so-wild things are: Computers in the courtroom, the federal rules of evidence, and the need for institutional reform and more judicial acceptance', Harvard Journal of Law and Technology, Volume 13, 2000, 161-302.

${ }^{4}$ Elizabeth C. Wiggins, 'What we know and what we need to know about the effects of courtroom technology', William \& Mary Bill of Rights Journal, Volume 12, 2003, 731-744; Neal Feigenson and Christina Spiesel, Law on Display: The Digital Transformation of Legal Persuasion and Judgement, (2009, New York: NYU Press).

${ }^{5}$ Neal Feigenson, 'Visual Evidence', Psychonomic Bulletin and Review, Volume 17, Issue 2, 149-154

${ }^{6}$ Saul M. Kassin and Megan A. Dunn, ' Computer-animated displays and the jury: facilitative and prejudicial effects', Law and Human Behaviour, Volume 21, 1997, 269-281.
} 
manipulate judgements for believing that a person could have fallen or jumped from a building, dependent upon the inclusion of supporting or contradictory animation evidence. Another study addressed similar questions over the inclusion of animation evidence from a more cognitiveinformation processing perspective. ${ }^{7}$ Morell compared animations with more static pictorial illustrations and discovered that, in conjunction with expert testimony, recall following a two-week delay was improved when subjects had observed an animation. Additionally, a number of other experiments have also served to highlight that judgments constructed around colour, ${ }^{8}$ angle of view, ${ }^{9}$ order effects ${ }^{10}$ and familiarity with case ${ }^{11}$ can be influenced by the presence or manipulation of an animation. Dunn and colleagues reviewed the extant literature and suggest that whilst there appears to be a potential effect from the use of animations on court decisions, we nevertheless understand little about why and under what circumstances this is problematic. ${ }^{12}$

There are, however, also a number of fundamental issues associated with utilising these approaches to investigate the wider influence of multi-media in court. The first is that they seldom acknowledge the fundamental problem with research into juries more generally. ${ }^{13}$ The mock juror is largely 'artificial' in that their decisions - most usually a binary guilty or notguilty - lack ecological validity. In essence, without formal accountability for decisions, jury research is limited in its potential to draw reliable and valid

\footnotetext{
${ }^{7}$ Linda C. Morell, ' New technology: experimental research on the influence of computer-animated displays on jurors', Southwestern University Law Review, Volume 28, 1999, 411-415.

${ }^{8}$ Gareth Norris and Heather Reeves, 'The effects of stereotypes on perceptions of speed and culpability: the impact of animation evidence', International Review of Law and Technology, Volume 26, 2012, 37-48.

${ }^{9}$ Gareth Norris, 'Effect of animation angle on perceptions of culpability and speed in a road traffic accident', Psychiatry, Psychology and Law, Volume 20, Issue 2, 2013, 248-254.

${ }^{10}$ Gareth Norris, 'Order effects in animated sequences of Computer Generated Evidence (CGE)', Psychiatry, Psychology and Law, Volume 20, Issue, 6, 2013, 909-920.

${ }^{11}$ Robert B. Bennett, Jordan H. Leibman, and Richard E. Fetter, 'Seeing is believing; or is it? An empirical study of computer simulations as evidence', Wake Forest Law Review, Volume 34, 1999, 257-294.

12 Dunn, Salovey and Feigenson, 244.

${ }^{13}$ David DeMatteo and Natalie Anumba, 'The Validity of Jury Decision-Making Research', in Joel Lieberman and Daniel Krauss, Jury Psychology: Social Aspects of Trial Processes (2009, Dartmouth: Ashgate), Chapter 1.
}

inferences. ${ }^{14}$ Secondly, empirical studies by their very nature seek to emulate the experimental design by manipulating one or two significant variables in order to test the effect on the outcome. ${ }^{15}$ Again, this is overly simplistic; during the course of a trial many pieces of evidence and testimony are introduced and cross-examined. Some of these may be struck from the record and others may be discredited. Judges may impose legal standards of proof and guidance on the way the law is to be imposed. ${ }^{16}$ Whilst the animation may be influential, it does not appear in isolation. Hence, it is necessary to consider how animations and CGE fit into the wider theoretical models of juror decision making in order for us to appreciate where in the process they may exert undue influence and the mechanisms which may limit this potential to prejudice a trial.

\section{Models of juror decision making}

Early mathematical models of juror decision making used Bayesian reasoning to demonstrate the mental processes undertaken by jurors during a trial. ${ }^{17}$ In its basic form, Bayes Theorem is a relatively simple mathematical rule which incorporates hypothesis testing alongside probability estimates. Specifically, it serves to calculate conditional probabilities from a range of likely scenarios. Bayes' theorem is stated mathematically as the following simple form:

$$
P(A / B)=P(B / A) P(A) /(P(B))
$$

For proposition A and evidence B,

$P(A)$, the prior probability, is the initial degree of belief in $A$.

$P(A \mid B)$, the conditional probability, is the degree of belief having accounted for $B$.

The quotient $P(B \mid A) / P(B)$ represents the support $B$ provides for $A$.

\footnotetext{
${ }^{14}$ Brian H. Bornstein, 'The ecological validity of jury simulations: Is the jury still out?', Law and Human Behavior, Volume 35, 1999, 7591.

${ }^{15}$ Brian H. Bornstein and Sean G. McCabe, 'Jurors of the absurd. The role of consequentiality in jury simulation research', Florida State University Law Review, Volume 32, 2005, 443-467.

${ }^{16}$ Richard L. Wiener, Daniel A. Krauss, D. A. and Joel D. Lieberman, 'Mock jury research: Where do we go from here?', Behavioral Sciences and the Law, Volume 29, 2011, 467-479.

${ }^{17}$ Reid Hastie, 'Introduction', In Reid Hastie, general editor, Inside the Juror: The Psychology of Juror Decision Making (1993, New York: Cambridge University Press), Chapter 1.
} 
Hence, for any particular outcome (A), we are interested in knowing how much can be predicted by something else occurring (B) and vice-versa. Bayesian models of juror decision making assume that decision making is sequential and multiplicative; as each new piece of information (evidence) is received the juror multiplies the probability of it occurring by the initial estimation of guilt. ${ }^{18}$ When deliberation is over, the juror will then compare their approximation of guilt with their threshold for conviction and vote either guilty or not guilty.

Bayesian models have not received much support from empirical studies in this area; however, Bayesian reasoning has been observed in a number of legal cases. Firstly, what is known as the defendants/prosecutors fallacy shows how conditional probability is widely misunderstood, not just by jurors, but also barristers and judges. The often cited case of Sally Clark demonstrated how Bayesian estimates were incorrectly presented and resulted in a potential error in her initial conviction. Secondly, Bayesian reasoning was specifically instructed to form the basis of legal inference in the case of $R v$ Adams. ${ }^{19}$ Here, the forensic expert correctly instructed jurors that the possibility of a match between the suspect and Adams was 1:200 million. ${ }^{20}$ The statistician employed to instruct the jury did an admirable job of explaining how Bayesian reasoning worked, but despite all of the other evidence suggesting innocence (incorrect age, false line-up identification and proven alibi), the jury subsequently convicted Adams in both the original and retrial. Hence, the applicability of Bayesian models is perhaps limited to a theoretical discussion as it appears in practice that these are overly complex to operationalise. In relation to where CGE and animation evidence 'fits' within a Bayesian perspective, it again appears less problematic. Using this mathematical model, any animation presented would be treated in much the same way as all the other evidence; jurors would multiply whether the event unfolded as demonstrated in line with their prior assumption of guilt or innocence (between 0-1).

\footnotetext{
${ }^{18}$ Reid Hastie, 'Algebraic models of jury decision making', in Reid Hastie, general editor, Inside the Juror: The Psychology of Juror Decision Making (1993, New York: Cambridge University Press), Chapter 4.

${ }^{19} R v$ Adams [1996] 2 Cr App R 467, [1996] Crim LR 898, CA and $R$ $\checkmark$ Adams [1998] 1 Cr App R 377, The Times, 3 November 1997, CA.

${ }^{20}$ Peter Donnelly, 'Appealing Statistics', Significance, Volume 2, Issue 1, 2005, 46-48.
}

The only potential issue for considering CGE in the Bayesian tradition is whether the animation could lead the 'mental meter' to reach one of the critical or absolute values ( 0 or 1 ), whereby it would essentially 'freeze' and remain so until verdicts were requested. Potentially a very convincing or poorly prepared animation could tip the scales to convict or acquit in a similar way in which the DNA evidence affected the decision in $R v$ Adams. The limitation of this explanation is that we are unsure about why this might occur and exactly how the animation might interact with other evaluations of evidence and estimations of guilt and innocence. Stochastic Processing Models on the other hand, incorporate error variance into the decision making system. ${ }^{21}$ Stochastic reasoning also involves the estimation of probabilities; however, it differs from Bayesian and other more traditional algebraic models of juror decision making, in that it contrasts a number of different potential outcomes for each event and evaluates these against their probable outcome. The first to propose the stochastic process were Ewart Thomas and Anthony Hogue, ${ }^{22}$ themselves building on the work of Davis some years earlier with a particular interest in the variability of decision making based upon jury size.

Stochastic processes are essentially explanations of events which occur continuously, yet independently. In a similar way to Bayesian predictions, stochastic processes are probability models which the final outcome is unknown yet importantly have some outcomes which are more likely than others. From a theoretical perspective, stochastic reasoning is a type of Poisson model in that it can be used to predict the outcome of independent events that have a variable pattern. Stochastic models have been shown to be useful in accounting for a range of human behaviour. For example, we could apply Poisson models to understanding such phenomenon as the number of buses that will arrive at a stop or number of people who visit a restaurant in a set period. Kerr suggests that in legal situations, stochastic reasoning can be applied to evaluating the diversity of case-specific knowledge when particular jurors are assigned to

\footnotetext{
${ }^{21}$ Norbert Kerr, 'Stochastic models of jury decision making', in Reid Hastie, general editor, Inside the Juror: The Psychology of Juror Decision Making (1993, New York: Cambridge University Press), Chapter 5.

22 Ewart A. Thomas and Anthony Hogue, 'Apparent weight of evidence, decision criteria, and confidence ratings in juror decision making', Psychological Review, Volume 83, Issue 6, 1976, 442-465.
} 
cases. In the dominant Poisson model (of which several were evaluated by Kerr), two main phases are undertaken. The first involves an estimation of the weight of evidence for or against a defendant. Secondly, this weight is considered against a decision criterion - assumed to be the legal standard of proof and if this exceeds this critical value, then a guilty verdict will be recorded. The closer these are, the more confident the juror is in their final decision. ${ }^{23}$ One of the main limitations of the stochastic model of juror decision making is that it does not elaborate on the actual cognitive processes and individual differences between jurors; advocates of the Poisson model are more interested in the net end result than the underlying influences initiating this outcome.

However, one particular and relatively unique aspect of this account of juror decision making processes which has potential relevance to CGE is what is referred to as the 'Critical Event' in stochastic models. ${ }^{24}$ The critical event is a feature of stochastic reasoning whereby when a particularly compelling piece of evidence or testimony is received, the 'mental meter' of defendant guilt is frozen at this point. Subsequent testimony is immaterial in altering decisions, and if the opinion of the defendant's culpability falls within the parameters of their conviction threshold, then a guilty verdict will be recorded. For example, in the trial of OJ Simpson, the defendant was asked to try on a blood soaked glove found at his house. ${ }^{25}$ The dramatic scene shown at the televised trial saw Simpson struggling to pull the garment onto his hand (although there was later suggestion that this evidence may have been tampered with $\left.{ }^{26}\right)$. The resulting instruction to the jury 'If it doesn't fit, you must acquit' was for many the pivotal point in the trial - the 'critical event' in

\footnotetext{
${ }^{23}$ Lora M. Levett, Erin M. Danielson, Margaret B. Kovera, and Brian L. Cutler, 'The psychology of jury and juror decision making', in Neil Brewer and Kipling D. Williams, Psychology and Law: An Empirical Perspective (2005, New York: The Guilford Press), Chapter 11.

${ }^{24}$ Kerr, 116

${ }^{25}$ Linda Deutsch, 'OJ Simpson Murder Trial: "If It Doesn't Fit, You Must Acquit"', NBC Los Angles, 11 June 2014,

http://www.nbclosangeles.com/news/local/OJ-Simpson-20-YearsLater-Glove-Fit-Darden-Dunne-Murder-Trial-of-the-Century262534821.html.

${ }^{26}$ Philip Sherwell, 'OJ Simpson murder trial glove 'was tampered with' by defence lawyer Johnnie Cochran, claims prosecutor', The Telegraph, 8 September 2012,

http://www.telegraph.co.uk/news/worldnews/northamerica/usa/95308 38/OJ-Simpson-murder-trial-glove-was-tampered-with-by-defencelawyer-Johnnie-Cochran-claims-prosecutor.html .
}

stochastic terms. Quite feasibly, an animation could take the form of the critical event.

The variable nature of the stochastic models assumes that various different accounts or estimates can result from the evidence presented. Holding several scenarios in contention would appear to be representative of good decision making, whereby a number of hypotheses are evaluated and eliminated. The Story Model of juror decision making, on the other hand, contends that jurors do not necessarily hold one 'global' judgment of guilt or innocence throughout a trial, but rather create a number of scenarios or stories from the evidence received. ${ }^{27}$ Unlike the previous mathematical explanations, Pennington and Hastie's Story Model alternative is considered to be a cognitive or 'explanation-based' model, which instead relies upon the assumption that jurors are active participants in a trial and will weigh up the validity and importance of evidence in line with their previous knowledge and experiences.

In order to assimilate the evidence received during a trial, the theory presumes that jurors integrate these together in a causal chain of events (in essence a story). In any given trial, information is not generally presented chronologically, but rather in a disjointed and artificial sequence. Additionally, jurors themselves are not permitted to ask questions of witnesses and experts and hence their accounts may be incomplete or ambiguous. Jurors are then given the task of creating these causal pathways into an accessible narrative which may involve estimation and reliance on previous similar situations in order to complete any missing or incomplete connections. Pennington and Hastie's Story Model has perhaps been the most widely accepted of juror decision making models, if only because it is relatively easier to comprehend than algebraic alternatives. ${ }^{28}$

Additionally, the story metaphor 'fits' into the way we generally think about criminal events in particular; popular media portrayals of the CSI genre have been successful by exploiting our quest to construct meaningful accounts, even potentially generating their own influence on jurors. Importantly, the 'CSI Effect' is assumed to be a result of this requirement to build complete and consistent accounts of events;

\footnotetext{
27 Nancy Pennington and Reid Hastie, 'The story model for juror decision making', in Reid Hastie, general editor, Inside the Juror: The Psychology of Juror Decision Making (1993, New York: Cambridge University Press), Chapter 8.

${ }^{28}$ Levett, Danielson, Kovera and Cutler, 372
} 
missing or unexplained evidence hinders or creates doubt in this process. ${ }^{29}$ Hence, the use of CGE and story model explanations is remarkably similar in scope to the theory of the story model of jury decision making proposed by Pennington and Hastie in that it creates a logical sequence of events in the mind of the observer [the juror] and evidence is then assimilated into this account. Issues of Coverage and Coherence (including Consistency, Plausibility and Completeness) are the vehicles with which the story is aligned with the version of events proposed by defence or prosecution. ${ }^{30}$

There are a number of empirical studies which have provided support for the Story Model as a relatively acceptable representation of how jurors go about making legal decisions in a case. A review in 2005 by Levett and colleagues led them to conclude:

\section{'[...] jurors were more likely to find the defendant guilty in those cases in which the evidence favoured guilt when they read the evidence in story form [...] when it was easier for the jurors to create a story, they were more likely to decide in accordance with the preponderance of evidence. ${ }^{31}$}

Hence, 'assisting' the jury to make a consistent, plausible and complete story is likely to favour a guilty verdict and the use of CGE would appear to be a major facilitator of this process. Potentially it does this through a schema known as the Simulation Heuristic or Counterfactual Thinking. Developing on work related to the Availability Heuristic (whereby we test different explanations based upon our existing knowledge of similar events), the simulation heuristic was proposed by Daniel Kahneman and Amos Tversky in 1982 as a more complete account of how we develop and test multiple versions of events to understand what we believe ultimately occurred and why. ${ }^{32}$ Importantly, the simulation heuristic - as with all judgment biases - is in essence a mental shortcut allowing us to make cognitive demands more manageable or to decrease dissonance and

\footnotetext{
${ }^{29}$ Simon A. Cole and Rachel Dioso-Villa, 'Investigating the CSI Effect Effect: Media and Litigation Crisis in Criminal Law', Stanford Law Review, Volume 61, 2008-2009, 1335-1374.

30 Pennington and Hastie, 199.

${ }^{31}$ Levett, Danielson, Kovera and Cutler, 375

32 Daniel Kahneman and Amos Tversky, 'The simulation heuristic', in Daniel Kahneman, Paul Slovic, Amos Tversky, Judgment under uncertainty: heuristics and biases, (1998, Cambridge: Cambridge University Press), Chapter 14.
}

uncertainty: 'The ease with which the simulation of a system reaches a particular state is eventually used to judge the propensity of the (real) system to produce that state. ${ }^{\prime 33}$ We favour explanations that are easy to understand over ones which require more taxing mental processing to reach firm conclusions.

In testing the simulation hypothesis, Kahneman and Tvserky presented subjects with two accounts of people whom had missed their flights by either 5 or 30 minutes. Although the outcome was the same both were unable to travel - over 90 per cent of the participants in the study suggested that the person that had arrived at the airport after 5 minutes had elapsed since their flight closed would be the more disappointed. It is assumed that in mentally recreating events, people opt for explanations which are less complex to mentally represent (that is creating reasons as to why we might be 30 minutes late is more multifaceted than, for example, getting stuck in traffic and being only 5 minutes late). Similarly when requested to mentally 'undo' a vehicle collision scenario, subjects opted for easier to visualise explanations rather than the most probable which was that the two cars had simply arrived at the same place at the same time: '[...] cognitive rules that govern ease of mental undoing [...] could be called counterfactual emotions because of their dependence on a comparison of reality with what might or should have been. ${ }^{34}$ Whereas Bayesian and Stochastic models of decision making (including jury models) assume some prior estimation of probability, counterfactual thinking suggests those events which are simpler to mentally recreate will emerge as the most plausible and likely.

In considering the likely interface with the Simulation Heuristic and Story Model with CGE - and ultimately the potential influence upon jury decision making we can examine a number of elements that make up this judgement bias to explain how this process is aided by the animation. What is referred to as a downhill change is where an incongruent or surprising element of a story is removed to increase the internal consistency; conversely, an uphill change is where an incompatible element is introduced and decreases the plausibility of the account. During their experiments, Kahneman and Tversky found little evidence of people making uphill changes; the preference for removing

\footnotetext{
${ }^{33}$ Kahneman and Tversky, 201-202.

${ }^{34}$ Kahneman and Tversky, 205
} 
inconsistent elements from a story is seemingly the least mentally taxing. Hence, we can predict that if the simulation heuristic is present in legal reasoning - as suggested in one study by Miller and McFarland ${ }^{35}$ the use of animation evidence can make a significant impression on the comprehension and assimilation of evidence into a complete story.

The issue of whether an animation is a precise reenactment or merely an illustration of what probably happened is more than a point of debate. In the recent trial, acquittal and re-trial in Italy of the defendants in the Meredith Kercher murder, much has been made of the equivocal forensic evidence (DNA on a knife and bra clasp), further confounded by questionable crime scene documentation and management. ${ }^{36}$ In addition, the conflicting accounts of multiple defendants and a singular guilty plea make this a complex case to unravel. What we can be sure of is that Meredith Kercher was murdered, and to some extent how the physical injuries resulted in her death. The more important fact - the one for the jury - is by whom and why. In the trial of Amanda Knox and Raffaele Sollecito (an additional co-defendant, Rudy Guede, had already pleaded guilty), much was made about their probable involvement, yet there is not really any dispute that Ms Kercher was killed. In reality, the fact that both Knox and Sollecito are jointly implicated is somewhat immaterial in relation to how Kercher died, i.e. the physical wounds and how they were inflicted. Had, for example, Knox's lawyers argued that only Sollecito could have inflicted certain wounds due to his height or strength, then possibly the animated sequence presented before the court might have had some evidentiary value. However, there is little dispute over the eventual outcome, and given that there are a myriad of potential scenarios which might fit with the contested evidence in this case, not only does the animation seem ambitious, but potentially prejudicial to the case. As one commentator suggested: 'The animation now seems to have been a mere fantasy, an animated version of the prosecution's theory featuring Amanda Knox as a sex-crazed femme fatale. ${ }^{37}$

${ }^{35}$ Dale T. Miller and Cathy McFarland, 'Counterfactual thinking and victim compensation: A test of norm theory', Personality and Social Psychology Bulletin, Volume 12, Number 4, 1986, 513-519.

${ }^{36}$ Leila Schneps and Coralie Colmez, Math on trial. How numbers get used and abused in the courtroom, (2013, Basic Books); Candace Dempsey, Murder in Italy, (2010, Berkley Books).

${ }^{37}$ Richard K. Sherwin, 'The Digital Trial', Project Syndicate, 12 October 2011, https://www.project-syndicate.org/commentary/thedigital-trial .
We may never know who killed Meredith Kercher, although at the time of writing, at least one person is serving a life-sentence for their guilty plea surrounding their involvement. What is quite apparent is that the animation is largely superfluous to increasing the juries understanding of what happened in the hours, days, weeks, months leading up to Meredith's death. ${ }^{38}$ Unlike the animation-hybrid used in the Murtha trial, ${ }^{39}$ there is no point of reference for a juror to establish the validity of the sequence of events. ${ }^{40}$ The 20 minute HD animation which allegedly cost nearly quarter of a million dollars to produce - uses Avatars to represent the events of November, 2007. There is no CCTV footage or definitive forensic material (e.g. a bloody handprint), to link the accused to the murder as depicted by the prosecution. Unlike the case of Murtha, there is no testimony or video footage to reveal what happened and what decisions were made; at best, it is a tentative attempt to make some sense out of a myriad of circumstantial evidence and flawed forensic analysis. Unfortunately, in attempting to recreate such events, jurors may fall foul of another decision error known as the Hindsight Bias, which has been shown to have an effect on legal-type decisions involving animation evidence.

\section{Juror bias and judgement heuristics}

The main criticism against just decision models particularly the mathematical models - is that they are poor in explaining the actual cognitive processes which jurors make throughout a trial. Jurors operate as decision makers in environments of uncertainty: 'That different arguments are possible from the same evidence is one reason why there is a trial in the first place. ${ }^{41}$ The more equivocal the inputs (evidence, testimony, etc.), the more difficult the decision process becomes for the juror. When there is doubt or complexity associated with certain judgments, then

\footnotetext{
${ }^{38}$ Gareth Norris, 'The use (and abuse) of computer generated exhibits in court', The Brief (Tort, Trial and Insurance Practice Section - American Bar Association), Volume 40, 2011, 10-23.

${ }^{39}$ Connecticut v. Murtha (No. CR03-0568 598T) (Conn. Super. Ct. 2006 - unpublished) (possibly State of Connecticut v. Murtha,). See Feigenson and Spiesel, pp. 92-98 for an outline of the facts.

${ }^{40}$ Barry Leibowitz, 'Amanda Knox prosecutors investigated for Meredith Kercher "murder video"', CBS News, 1 May 2102, http://www.cbsnews.com/news/amanda-knox-prosecutorsinvestigated-for-meredith-kercher-murder-video/.

${ }^{41}$ David Schum, 'Argument Structuring and Evidence Evaluation', in Reid Hastie, general editor, Inside the Juror: The Psychology of Juror Decision Making (1993, New York: Cambridge University Press), Chapter 7, 175.
} 
heuristics and biases can result, leading to illogical and erroneous outcomes. In some respects, animations and CGEs serve to simplify this decision making process, although in doing so potentially exert undue influence over the juror. These in turn may render unsafe verdicts by introducing or exploiting specific heuristics of their own. Research into jury decision making suggests that the complexity of the trial process is problematic for achieving optimum verdicts based on the evidence and legal principles involved. ${ }^{42}$ Some years ago in their review of The American Jury, Harry Kalven and Hans Zeisel commented:

'It has not infrequently been charged that the modern jury is asked to perform heroic feats of attention and recall well beyond the capacities of ordinary men. A trial, it has been argued, presents to the jury a mass of material it cannot possibly absorb, and presents it in an artificial sequence which aggravates the jury's intellectual problems. ${ }^{\prime 43}$

Hence, the models of jury decision making discussed in the previous section, serve to illustrate the way in which verdicts are reached. Understandably, they can be complex and multi-faceted; CGEs have developed in response to the difficult nature of this task and aim to simplify the overall process. Seemingly, the Story Model emerges with the most empirical support and also someway fits into the process animations seek to instil on the juror - a seamless and ready-made account of the crime or incident.

However, as was previously discussed, the Story Model shared a basic theoretical connection with the Simulation Hypothesis proposed by Kahneman and Tversky - itself prone to errors of judgement and bias. The Simulation Hypothesis has generated a range of theoretical research which is generally referred to as counterfactual thinking, and herein lie some of the problems with the Story Model in relation to CGE. The link between counterfactual reasoning and other cognitive biases has also been explored, with the Hindsight Bias being implicated as a potential shared cognitive process under certain circumstances. ${ }^{44}$ In its

\footnotetext{
42 Henry Kaptein, 'Burdens of evidence and proof: why bear them? A plea for principled opportunism in (leaving) legal factfinding (alone)', in Hendrik Kaptein, Henry Prakken and Bart Verheij, general editors, Legal Evidence and Proof: Statistics, Stories, Logic, (2009,

Farnham: Ashgate Publishing), Chapter 1.

${ }^{43}$ Harry Kalven and Hans Zeisel, The American Jury, (1966, Boston: Little Brown and Co.), 149.

${ }^{44}$ Neal, J. Roese, 'Twisted Pair: Counterfactual Thinking and the Hindsight Bias', in Derek J. Koehler and Nigel Harvey, general
}

basic form, the hindsight bias serves to influence decision making processes in the sense that we assume events were more predictable when we subsequently know the outcome. ${ }^{45} \mathrm{~A}$ trial is one such example; very often we know the charges under deliberation, but due to the hindsight bias we are unable to fully appreciate that information known after the event was previously unavailable or potentially irrelevant. For instance, during the investigation into the Columbia Space Shuttle accident, the presence of a known defective component almost lead to criminal charges of negligence. Terrorist attacks are another good illustration. In the months after the attacks on 11 September 2001, Americans were significantly more likely to overestimate the level of risk posed by terrorists before the event, though relatively few even knew of the existence of Al Quada beforehand. In some instances, the hindsight bias can form the basis of conspiracy theories whereby major disasters, for example, Hurricane Katrina, are assumed to be 'known' and predictable and the limited government response indicative of wider social and political motives. As Baruch Fischoff notes: '[people] not only tend to view what has happened as inevitable, but also tend to view it as having been 'relatively inevitable' before it happened.' 46

Returning to the legal situation, the hindsight bias is particularly problematic in the court, as jurors are generally aware of what has happened and then asked to reassess that likelihood in relation to the evidence presented and legal standard of proof. ${ }^{47}$ Such situations serve to escalate the problems associated with this specific heuristic. Particularly in cases of negligence and malpractice, whether the defendant(s) could have reasonably known certain information or acted upon it is almost impossible to ascertain given the influence of hindsight.

Assessments of risk of dangerousness by psychiatrists are by their very nature notoriously unreliable; yet when incidents do occur, mental health professionals

editors, Blackwell Handbook of Judgement and Decision Making, (2008, Wiley-Blackwell), Chapter 13.

${ }^{45}$ Jonathan Baron, Thinking and Deciding, (2008, Cambridge: Cambridge University Press), 4th Edition.

${ }^{46}$ Baruch Fischhoff, 'Hindsight \# foresight: The effect of outcome knowledge on judgment under uncertainty', Journal of Experimental Psychology: Human Perception and Performance, Volume 1, 1975, 288-299.

${ }^{47}$ Gordon V. Rose and James R. P. Ogloff, 'Evaluating the comprehensibility of jury instructions: A method and an example', Law and Human Behavior, Volume 25, 2001, 409-431. 
are often criticised for not being aware of the warning signs. Attempts at de-biasing have received mixed empirical support, and efforts to get participants in studies to consider alternative scenarios have shown only a minimal sway on reducing the hindsight bias. In some respects, the trial process does present different sides of a story, and cross examination also seeks to highlight errors and omissions, including where decision makers may have been potentially unaware of the consequences of their actions.

However, research has shown that animations presented in court can exert significant - more than double - the influence than less 'dynamic' textual descriptions can. Neal Roese and colleagues identify one primary concern for animation evidence in relation to the hindsight bias in the form of memory updating. ${ }^{48}$ Specifically, the ability of people to recapture earlier memories when new associations are created in memory is compromised when a misattribution of processing fluency is subjectively felt: '[...] when a coherent causal explanation accounts for the outcome [...] when case relevant information feels familiar because of prior exposure [...] and when case relevant information feels subjectively easy to bring to mind. Computer animation may increase hindsight bias because the clarity of the visual presentation enhances processing fluency. ${ }^{49}$ In other words, the animation makes the account more simple to recall and hence 'tricks' us into inferring that this ease of processing is actually a result of more familiarity than actuality.

In relation to road traffic accidents in particular, the issue of hindsight is fundamental to ascertaining the responsibilities and actions of all parties involved:

'The science of accident reconstruction is being naively misused by inviting and exacerbating hindsight bias when passing judgment on a driver's unsuccessful response to avoid an accident. By focusing attention on the outcome, on how the driver should not have responded, and on how she or he could have done better, an accident reconstruction diagram can appropriately be called a hindsight diagram. A foresight diagram is offered to emphasize the uncertainty and lack

\footnotetext{
${ }^{48}$ Neal J. Roese, Florian Fessel, Amy Summerville, Justin Kruger and Michael A. Dilich, 'The Propensity Effect: When Foresight Trumps Hindsight', Psychological Science, Volume 17, Issue 4, 2006, 305-310.

${ }^{49}$ Roese, Fessel, Summerville, Kruger and Dilich, 305
}

of information that confronted the reactive driver when the threat first became apparent so that those charged with the task of determining cause or attributing fault can better appreciate the situation that existed at that most relevant point in time. ${ }^{50}$

The question of whether a driver of a car could and would act in a particular way is difficult to re-create, although we can be fairly sure that jurors will rely upon their own experiences of driving and - in hindsight - speculate as to what they would have done in the same situation. Certainly, with the value of time and an appreciation of the outcome, this is problematic.

The link between counterfactual thinking and the hindsight bias is not clear-cut; Roese and Vohs identify situations whereby counterfactuals could actually reduce hindsight errors. ${ }^{51}$ However, they caution that: '[...] when counterfactual thinking spotlights a prominent antecedent cause that furnishes a satisfying explanation for the outcome [...] then the counterfactual contributes to greater hindsight bias by way of sensemaking. ${ }^{52}$ Hence, in situations high in ambiguity or where the causal chain is of relevance (such as in legal trials), then counterfactuals may aggravate hindsight biases: 'The more a person can make sense of and inject meaning into the past, the greater the hindsight bias. ${ }^{.53}$ Further support for this link in legal situations comes from a series of experiments by Robbennault and Sobus: 'It is likely that both counterfactual thinking and hindsight bias can and do come into play when jurors are asked to make post hoc judgments regarding events. In particular, the moderating effect of counterfactual thinking on hindsight bias sets important limits on when hindsight bias will be observed. ${ }^{54}$ Ultimately, we can be fairly sure that when we are asked to reason contrary to the outcome we already know either to estimate its probability or understand the

\footnotetext{
${ }^{50}$ Michael Dilich, Dror Kopernik and John Goebelbecker, 'Hindsight judgement of driver fault in traffic accident analysis', Transportation Research Record: Journal of the Transportation Research Board, Number 1980, 2006, 1-7.

${ }^{51}$ Neal J. Roese and Kathleen D. Vohs, 'Hindsight Bias', Perspectives on Psychological Science, Volume 7, Issue 5, 411-426.

52 Roese and Vohs, 412.

${ }^{53}$ Roese and Vohs, 415.

54 Jennifer K. Robbennault and Mark, S. Sobus, 'An integration of hindsight bias and counterfactual thinking: decision-making and drug courier profiles', Law and Human Behaviour, Volume 21, Issue 5, 1997, 539-560.
} 
reasons why - then jurors are poor at remaining objective and to reason rationally. The use of CGE has been shown to significantly increase hindsight judgements and the link between the story model and counterfactual thinking (simulation hypotheses) also established. It is argued here that the use of CGE in some legal trials may increase the likelihood of jurors reasoning in a story model fashion and hence be overly exposed to the hindsight bias.

\section{Conclusion}

This article has set out some areas of concern over the use of CGE in legal proceedings and legal practices. Empirical studies have demonstrated that they exert an influence, and the emphasis here has been upon understanding how they are potentially problematic. It has been argued that in some instances they activate individual decision making heuristics and influence the more natural process by which we create mental representations of what has occurred. Similarly, there has been an attempt to assimilate this research into existing models of jury decision making. The Stochastic Process with its critical event was argued to be one possible explanation for why animations are seemingly so successful in court. The Story Model and the link with counterfactual thinking was again implicated as a potential area where CGE could demonstrate some influence; by minimising contradictory evidence and linking together testimony and evidence into a coherent and plausible plot was perhaps the most influential aspect. Potentially, many of these heuristics and models operate interdependently, with the 'better' animations seemingly able to exploit multiple angles of comprehension and assimilation in the mind of the juror.

Regardless of what the legal standards are for introducing CGEs into legal proceedings, it appears that there is relatively little understanding of the way in which these animations are potentially more than mere visual representations. The likely influence is significant; hence, all major trials have seemingly adopted the use of CGE as they would other consultants. Oscar Pistorius' 'Dream Team' of forensic experts included the Evidence Room - a US-based forensic animation company to produce visual reenactments of what occurred on the night of 14 February 2013. ${ }^{55}$ Legal professionals recognise the enormous power that multi-media presentations have in the court, yet the industry which has grown up to service this demand is largely unregulated. Similarly, the legal standards of admissibility are relatively nonexistent. In cases where animations have been excluded, it appears that the judge as 'gatekeeper' is the dominant model of legal admissibility. What we can be sure of is that the reason CGE is so popular is due to the recognition of the powerful influence it can have over jurors; what we are less convinced about is whether the use of CGE is potentially prejudicing trials by exerting undue influence on the decision making abilities of jurors. What was once a way to illustrate complex sequences of events or technical evidence has become a way of targeting hard-wired cognitive processes inherent to human decision making. It is hard to imagine other experts or innovative techniques being able to enter our courts without their credentials and practices meeting scientific or professional standards; CGE as a predominantly demonstrative aid largely circumnavigates these legal criteria of admissibility. From the review presented here, it is suggested that whilst the demonstrative aid of the moving image has its place in legal proceedings, tighter regulation, more research and careful implementation are called for.

\section{(C) Gareth Norris, 2014}

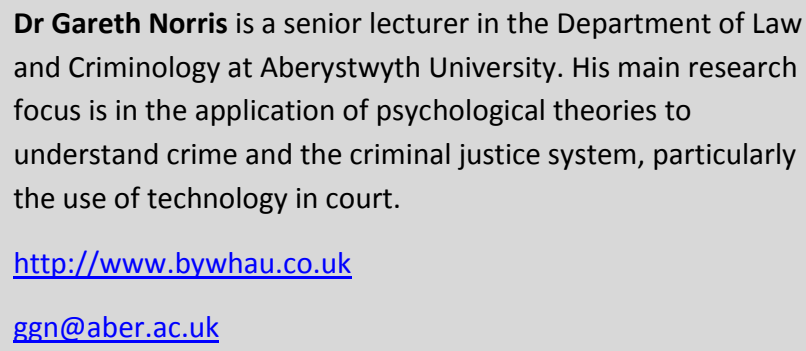

Dr Gareth Norris is a senior lecturer in the Department of Law and Criminology at Aberystwyth University. His main research focus is in the application of psychological theories to understand crime and the criminal justice system, particularly the use of technology in court.

http://www.bywhau.co.uk

ggn@aber.ac.uk

${ }^{55}$ http://time.com/\#5572/oscar-pistorius-dream-team-murder-trial/ . 